\title{
DESKRIPSI PEMANFAATAN NIPAH (Nypah fruticans Wurmb.) BERBASIS PENGETAHUAN LOKAL MASYARAKAT KAMPUNG NAREI KABUPATEN KEPULAUAN YAPEN
}

\section{(Description of Nipah Utilization [Nypah fruticans Wurmb.] Based on the Traditional Knowledge of Narei Villagers of Yapen District)}

Melianus Kayoi ${ }^{1}$ Jimmy F. Wanma ${ }^{1 凶}$ dan Bernadetta M. G. Sadsoeitoeboen $^{1}$

Jurusan Kehutanan, Fakultas Kehutanan Universitas Papua Manokwari, Papua Barat, 98314. Tlp/Fax: +62986211065.

\Penulis Korespondensi: Email: jimmywanma@yahoo.com

Diterima: 22 Mar 2018| Disetujui: 15 Apr 2018

\begin{abstract}
Abstrak
Penelitian ini bertujuan untuk mengetahui bentuk pemanfaatan nipah (Nypah fruticans Wurmb.) oleh masyarakat Kampung Narei, Distrik Yapen Barat, Kabupaten Kepulauan Yapen. Pengumpulan data primer dilakukan dengan teknik wawancara dan diskusi dengan pertanyaan secara semi struktural kepada responden yang telah ditentukan. Sementara dukungan data sekunder diperoleh dari stakeholder dan instansi terkait. Hasil penelitian memperlihatkan bahwa hampir sebagian besar $(92,16 \%)$ dari total responden telah memanfaatkan nipah dalam kehidupan sehari-hari selama lebih dari tiga tahun. Dalam pemanfaatan komponen tumbuhan nipah, terdapat tujuh bagian tumbuhan yang dimanfaakan antara lain: akar, tangkai buah, buah, tulang daun, tulang anak daun, anak daun dan pucuk daun. Sejauh ini proses transfer pengetahuan dilakukan secara informal melalui praktek langsung dan belum ada upaya konservasi dalam menjaga potensi dan ketersediaan jenis nipah.

Kata kunci: Potensi pemanfaatan, komponen tumbuhan, pengetahuan tradisional, hutan tropis.

Abstract
This study aimed to reveal types of use from nipah (Nypah fruticans Wurmb.) by local inhabitants of Narei village in west Yapen sub-district, Yapen district. Primary data were gathered by way of semi-structural interview and discussion based on the questionnaires made that was focused on the targeted respondents. In addition, secondary data were collected from related stakeholders and local governments. The result pointed out that most of the inhabitants $(92.16 \%)$ from the respondents have been utilized nipah in their daily life for more than three years. In daily use of nipah component, there was seven which have been actively taken such as: root, fruit stalks, fruit, midrib, veins, young leaf, and nypah's bud. Transfer knowledge over generations has been undertaken mostly in practice without theoretical teaching. It turned out that there was no preservative and conservation effort yet in regard to the long run plant's availability.
\end{abstract}

Keywords: Potential use, plant component, traditional knowledge, tropical forest. 


\section{PENDAHULUAN}

Nipah dapat dijumpai pada daerah berawa-rawa, terpengaru $\mathrm{h}$ oleh pasang surut air laut dan daerah-daerah muara sungai setelah formasi hutan mangrove. Nipah memiliki penyebaran yang cukup luas di Indonesia. Penyebaran meliputi wilayah kepulauan Sumatera, Kalimantan, Jawa, Sulawesi, Maluku, Papua. Penyebaran nipah di Papua relatif merata dari pantai utara dan pantai selatan. Nipah tumbuh secara liar dan membentuk rumpun-rumpun yang sangat lebat, kadangkadang merupakan hutan luas di daerah yang terpengaruh pasang surut. Oleh karena itu nipah juga sering disebut palem mangrove (Asmuruf 2006). Sebagai salah satu penyusun dari ekosistem mangrove, nipah (Nypah fruticans Wurmb.) mempunyai banyak fungsi dan manfaat (Subiandono dkk. 2011; Febriadi dan Saeni 2018). Namun sejauh ini masih sering dianggap sebagai tumbuhan liar yang tidak mempunyai manfaat, kecuali masyarakat di sekitar hutan nipah yang telah lama memanfaatkannya untuk memenuhi kebutuhan hidup mereka (Bandini 1996; Muthmainnah dan Sribianti 2016).

Kabupaten Kepulauan Yapen adalah salah satu kabupaten yang terletak di bagian utara Provinsi Papua dan merupakan salah satu daerah yang memiliki hutan mangrove, dengan formasi yang sangat luas di pesisir pantai hingga hilir sungai yang dapat melindungi gempuran ombak dan abrasi air laut (Badan Pusat Statistik Kabupaten Yapen 2017). Distrik Yapen Barat yang memiliki hutan nipah hampir di semua kampung yang berada di dalam kawasan Distrik Yapen Barat. Kampung Narei merupakan salah satu daerah penyebaran nipah yang menyebar disepanjang tepi sungai yang berair payau, dengan topografi datar, dan banyak mengandung lumpur. Salah satu tumbuhan yang hingga kini masih dimanfaatkan oleh masyakat Kampung Narei Disrtik Yapen Barat Kabupaten Kepulauan Yapen adalah Nipah. Penelitian ini bertujuan untuk mengetahui bentuk pemanfaatan nipah dari bagian tumbuhan oleh masyarakat Kampung Narei, Distrik Yapen Barat, Kabupaten Kepulauan Yapen. Hasil penelitian ini diharapkan dapat menjadi sumber informasi tentang pemanfaatan nipah bagi pihak terkait guna pelestarian dan pengembangan perekonomian masyarakat Kampung Narei, Distrik Yapen Barat Kabupaten Kepulauan Yapen.

\section{METODE PENELITIAN}

Penelitian ini dilaksanakan di Kampung Narei Distrik Yapen Barat Kabupaten Kepulauan Yapen selama satu bulan yakni dari Septmber s/d Oktober tahun 2017. Penelitian ini menggunakan metode deskriptif dengan teknik sensus. Variabel pengamatan terdiri dari variabel utama dan variabel penunjang dimana variabel utama yang dikaji meliputi: pengolahan nipah (bagian tumbuhan yang dimanfaatkan dan cara pemanfaatan), aspek sosial budaya (cara pengambilan, nilai budaya dari nipah, pola transfer pengetahuan dan pola konservasi). Sementara variabel penunjang yang dilihat antara lain keadaan umum lokasi penelitian yang akan diperoleh dari instansi terkait.

\section{Penentuan Responden dan Pengumpulan Data}

Penentuan responden dilakukan secara sensus. Yang termasuk responden adalah seluruh kepala keluarga yang 
berada di kampung Narei. Sementara untuk responden kunci terdiri dari tokoh adat, kepala suku dan tokoh masyarakat yang berada di Kampung Narei. Data yang dikumpulkan meliputi data primer dan data sekunder. Pengumpulan data primer dilakukan dengan teknik wawancara semi struktural dan observasi lapangan dengan menggunakan kuisioner yang telah disiapkan. Data sekunder berupa keadaan umum lokasi penelitian yang akan diperoleh dari kantor kampung, kantor distrik setempat maupun instansi terkait.

\section{Analisis Data}

Data yang dikumpulkan dianalisis secara tabulasi dan kemudian ditampilkan dalam bentuk tabel dan gambar.

HASIL DAN PEMBAHASAN

\section{Identifikasi Pemanfaatan Tumbuhan} Nipah, Pengelolaan dan Pemanfaatannya
Pemanfaatan tumbuhan nipah oleh masyarakat telah berlangsung secara turun-temurun. Tujuan pemanfaatan nipah oleh masyarakat tersebut adalah untuk memenuhi berbagai kebutuhan hidup mereka. Selanjutnya intensitas pemanfaatan nipah dan indikatornya serta pilihan disajikan pada Tabel 1. Hasil penelitian seperti pada Tabel 1 menunjukkan bahwa sebanyak 92,16\% masyarakat memanfaatkan tumbuhan nipah lebih dari 3 tahun, baik untuk tujuan ekonomi, perlengkapan rumah tangga maupun untuk perhiasan adat dan tidak ada masyarakat yang memanfaatkan tumbuhan nipah kurang dari 6 bulan. Hal ini karena masyarakat yang ada sudah sejak lama mendiami kampung Narei. Selanjutnya diketahui juga bahwa hanya $43,14 \%$ masyarakat yang selalu memanfaatkan tumbuhan nipah tersebut (secara rutin), selain itu diketahui juga bahwa hanya sebanyak 5,88\% masyarakat yang sangat tergantung pada tumbuhan nipah tersebut.

Tabel 1. Indikator pemanfaatan nipah oleh masyarakat kampung Narei.

\begin{tabular}{lccc}
\hline \multirow{2}{*}{ Indiaktor } & Opsi/Pilihan & \multicolumn{2}{c}{ Responden } \\
\cline { 3 - 4 } & & 0 & Jumlah \\
\hline Lama pemanfaatan & 0,6 & 2 & 0 \\
& 1 & 2 & 3,93 \\
& 3 & 47 & 3,93 \\
Keberlangsungan & $>3$ & 22 & 92,16 \\
& Ya & 29 & 43,14 \\
Ketergantungan & Tidak & 3 & 56,86 \\
Frekuensi (perhari) & Ya & 48 & 5,88 \\
& Tidak & 15 & 94,11 \\
& $1 \mathrm{kali}$ & 35 & 29,41 \\
& $2 \mathrm{kali}$ & 1 & 68,62 \\
& $3 \mathrm{kali}$ & 0 & 1,96 \\
& $>3 \mathrm{kali}$ & & 0 \\
\hline
\end{tabular}


Tabel 1 juga memperlihatkan bahwa pengambilan nira dari tumbuhan nipah oleh masyarakat kampung Narei adalah pada pagi hingga sore hari. Terdapat sebanyak $68,62 \%$ masyarakat yang mengambil 2 kali dalam sehari (pagi dan sore), sedangkan yang mengambil dalam 3 kali sehari sebanyak 1,96\% Pengambilan lebih dari 1 kali disebabkan produksi nirah perpohonnya sangat banyak, sehingga harus diambil lagi pada sore hari.

\section{Pemanfaatan Bagian Tumbuhan Nipah}

Dalam kaitannya dengan pemanfaatan tumbuhan nipak terlihat bahwa dari 10 bagian tumbuhan nipah, hanya 7 bagian yang dimanfaatkan dalam 20 jenis pemanfaatan. Akar dimanfaatkan hanya sebagai obat pengusir nyamuk. Itupun hanya oleh sebanyak 7,84\% masyarakat. Dikatakan bahwa masyarakat lebih memilih menggunakan obat pengusir serangga yang dipasarkan di toko/kios, karena mudah dan cepat didapatkan. Bagian tangkai juga hanya dimanfaatkan sebagai penghasil nira untuk membuat minuman Bobo. Sebanyak 76,47\%, masyarakat memanfaatkan tangkai buah sebagai sumber minuman/bobo untuk menambah penghasilan dalam memenuhi kebutuhan dalam rumah tangga. Selain itu sebanyak $7,84 \%$, masyarakat memanfaatkan minuman bobo tersebut sebagai obat tradisional penghilang rasa capek. Selain akar dan tangkai, masyarakat juga menggunakan buah nipah sebagai bahan makanan dan pengawet. Terdapat sebanyak $88,24 \%$ masyarakat memanfaatkan buah Nipah sebagai bahan makanan pengganti makanan ringan saat bekerja di dusun. Sebanyak 21,57 \% masyarakat menggunakan buah nipah yang tua sebagai bahan pengawet minuman bobo.
Selain itu sebanyak 35,29\% masyarakat menggunakan isi bagian dalam buah nipah sebagai bahan penangkapan tikus tanah. Hal ini disebabkan tikus tanah menyukai isi dari buah nipah.

Tulang daun hanya digunakan sebagai bahan pembuat para-para dan kayu bakar. Sebanyak $\quad 3,92 \% \quad$ masyarakat memanfaatkan tulang daun nipah sebagai bahan pembuat para-para sementara untuk menaruh peralatan kerja, makanan dan pakaian saat bekerja di kebun/dusun. Sebanyak $\quad 31,37 \%$ masyarakat memanfaatkan tulang daun nipah sebagai kayu bakar selama bekerja di dusun. Masyarakat tidak memanfaatkan tulang daun sebagai bahan pembuat dinding karena bahannya tidak kuat.

Jenis produk yang dibuat oleh masyarakat dari tulang anak daun adalah sapu, tapisan, gata-gata (peralatan makan seperti penjepit) dan bahan obor. Sebagian besar masyarakat menggunakan tulang anak daun nipah sebagai bahan pembuat gata-gata dan sapu, karena mudah didapat dan murah bila dibandingkan dengan peralatan yang dijual di toko. Selain tulang anak daun, masyarakat juga menggunakan anak daun sebagai bahan pembuat atap dan dinding rumah, bahan pembungkus makanan dan pembuat kipas dan pucuk daun sebagai kertas rokok, bahan pakaian dan pembuat peralatan dapur.

Batang, pelepah dan bunga tidak dimanfaatkan. Masyarakat tidak menggunakan batang nipah dan pelepah sebagai kayu bakar, dinding rumah dan lantai rumah karena bahannya tidak kuat, cepat hancur dan busuk. Demikian juga dengan bunga. Masyarakat tidak memanfaatkan bunga nipah karena tangkai bunga dari jenis nipah akan dimanfaatkan sebagai sumber penghasil 
nira dan juga buahnya dimakan dan digunakan sebagai bahan obat tradisional, peralatan berburuh. Hal ini berbeda dengan beberapa daerah di Papua yang umumnya memanfaatkan pelepah. Menurut Inwasef (2011) masyarakat di Kampung Mariarotu Distrik Kosiwo Kabupaten Kepulauan Yapen memanfaatkan potongan pelepah nipah yang sudah kering sebagai sumber energi pengganti kayu bakar. Beberapa daerah di Papua menggunakan tulang daun sebagai bahan konstruksi dinding rumah, sedangkan masyarakat kampung Narei hanya menggunakan daun nipah.

\section{Proses Pemanfaatan Bagian Tumbuhan Nipah}

Akar Tumbuhan Nipah

Masyarakat kampung Narei memanfaatkan akar dari tumbuhan nipah sebagai obat pengusir serangga (nyamuk, agas, dan lain-lain). Akar tumbuhan nipah yang digunakan adalah nipah yang sudah mati atau di serang penyakit, yang tercabut akibat banjir selanjutnya akar dijemur sampai kering sebelum digunakan dengan cara dibakar (asapnya sebagai obat pengusir nyamuk).

\section{Tangkai Buah}

Masyarakat

memanfaatkan tangkai buah nipah sebagai sumber penghasil nira untuk membuat minuman lokal/bobo. Bahan nira berasal dari tangkai buah tumbuhan nipah. Tangkai nipah yang sudah berbuah dibersihkan dan dijaga sampai tua kemudian digoyang dan di pukul-pukul selama satu bulan agar air nira dapat keluar dengan lancar, Selanjutnya buah nipah dipotong dari tangkainya dan dibiarkan meleleh/menetes selama 2-3 hari. Cara ini yang digunakan untuk mengetahui keluarnya air/nira dari tangkai buah keluar dengan lancar atau tidak. Jika air/nira telah keluar dengan lancar barulah dimulai dengan proses penyadapan atau pengambilan nira. Nira inilah yang akan digunakan sebagai bahan dasar pembuatan minuman lokal/ bobo. Masyarakat kampung Narei dalam memenuhi kebutuhan hidup sehari hari umumnya bekerja sebagai nelayan, petani, buruh bangunan. Masyarakat memanfaatkan minuman bobo sebagai ramuan untuk mengembalikan stamina akibat kelelahan setelah melakukan aktifitas sehari-hari.

\section{Buah}

Masyarakat memanfaatkan buah dari tumbuhan nipah sebagai bahan makanan, bahan obat tradisional dan bahan peralatan berburu. Buah nipah yang dimakan adalah bagian dalam buah yang sudah masak. Selain itu bagian buah yang tidak dimanfaatkan (kulit) dapat digunakan sebagai pengawet minuman bobo agar tahan lama. Caranya dengan menumbuk halus bagian kulit tersebut dan memasukannya ke dalam bambu sebagai wadah penampung. Selain itu masyarakat juga memanfaatkan buah nipah juga sebagai bahan umpan berburu tikus tanah. Bagian buah nipah yang dimanfaatkan adalah bagian buah kecil yang diambil dan dibelah menjadi dua. Selanjutnya diambil isi bagian dalamnya diletakkan ke dalam perangkap/jerat sebagai umpan. 

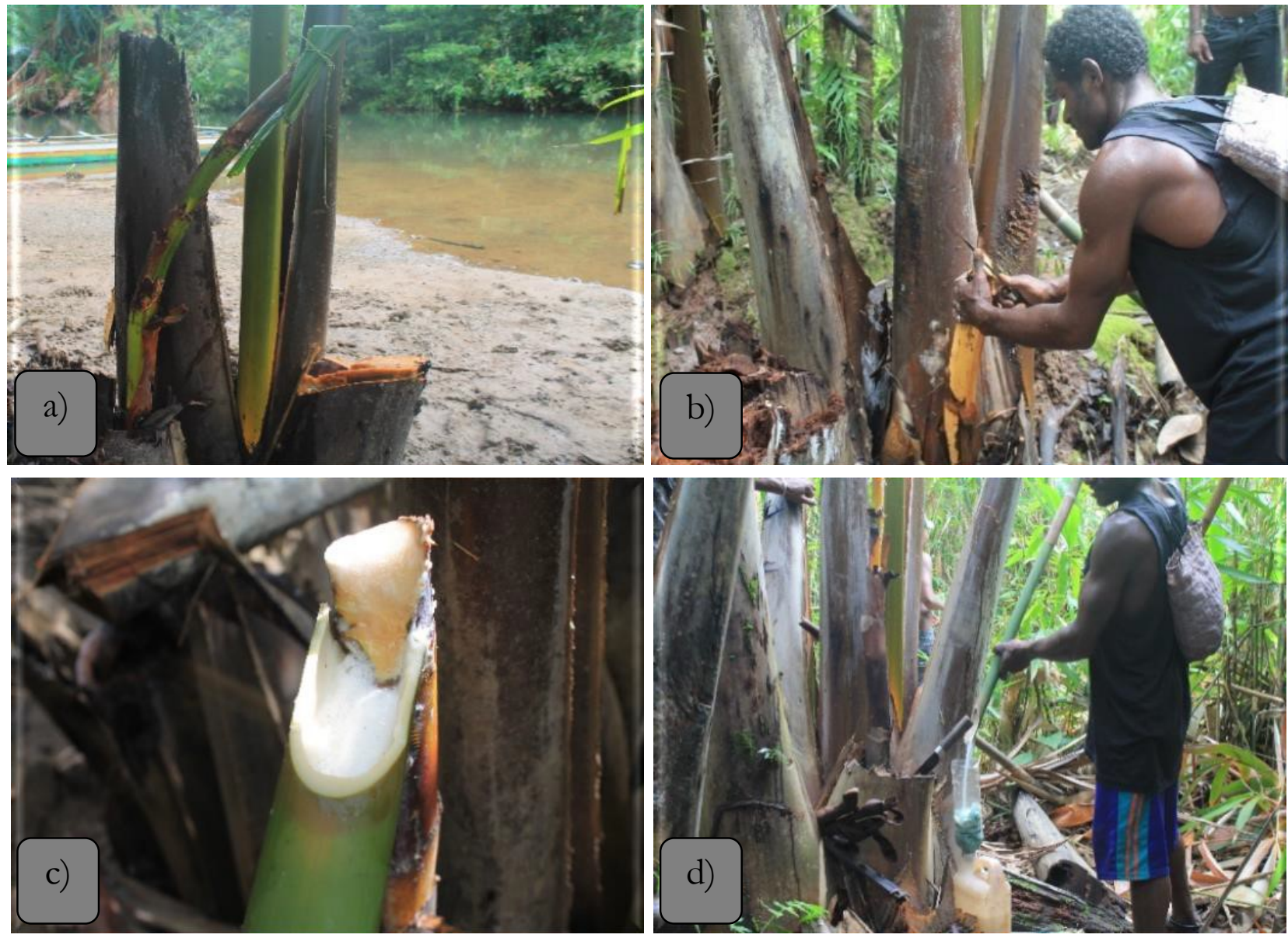

Gambar 2. a). Tangkai buah yang dipotong untuk dijadikan sebagai sumber nira, b). proses penyadapan nira/bobo, c). pemasangan bambu sebagai penampung nira, d). pemindahan nira ke dalam wadah.

\section{Tulang Daun}

Dalam kesehariannya masyarakat memanfaatkan tulang daun tumbuhan nipah sebagai bahan pembuat para para (bangku/meja lebar). Para para digunakan untuk meletakkan peralatan kerja, makanan, pakaian kerja saat bekerja. Para para dibuat dari tulang daun nipah yang keras atau telah tua dan telah dibersihkan daunnya serta dipotong sesuai ukuran yang diinginkan. Selain itu masyarakat juga memanfaatkan tulang daun nipah yang kering sebagai bahan bakar.

\section{Tulang Anak Daun (Lidi)}

Masyarakat memanfaatkan tulang anak daun dari tumbuhan nipah sebagai sapu, tapisan, peralatan makanan (gatagata papeda) dan obor. Tulang anak daun nipah yang digunakan sebagai sapu berasal dari daun nipah yang sudah dihilangkan bagian daunnya. Jumlah yang akan digunakan disesuaikan dengan kebutuhan . Untuk memanfaatkan tulang anak daun tumbuhan nipah sebagai tapisan, maka tulang anak daun yang sudah bersih selanjutnya dibuat anyaman 
tapisan. Bahan pembuat obor berasal dari ikatan tulang anak daun.

Anak Daun

Anak daun dari tumbuhan nipah digunakan oleh masyarakat sebagai bahan atap dinding rumah, pembungkus makanan, dan kipas api. Bahan atap berasal dari anyaman anak daun nipah yang sudah tua yang sudah dihilangkan bagian atas dari tulang anak daun.
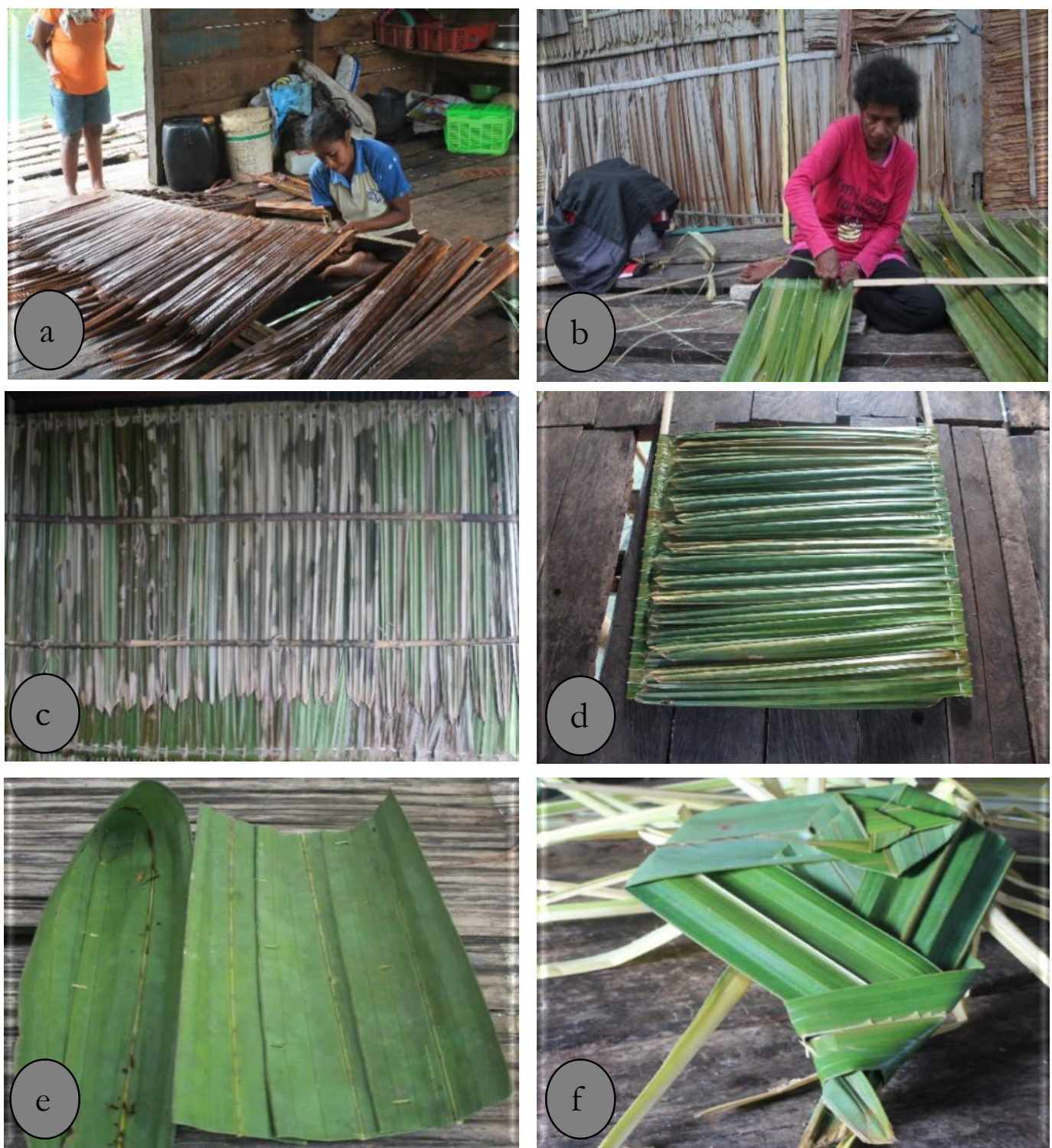

Gambar 6. Bentuk pemanfaatan daun nipah; a). proses menjahit atap rumah, b). proses menjahiat dinding rumah, c). dinding rumah yang sudah jadi, d). dinding rumah ukuran kecil (jendela rumah), e). pembungkus makanan, f). kipas api.

Sebagai pengikat anyaman digunakan tali dari bambu muda (loso loso), sedangkan sebagai penahan untuk menyusun anyaman daun sebagai atap rumah digunakan bambu yang sudah tua. Selain atap masyarakat juga 
memanfaatkan anak daun tumbuhan nipah sebagai dinding rumah. Cara yang di gunakan sama dengan atap rumah, hanya di susun secara vertikal. Anak daun nipah juga digunakan sebagai bahan pembungkus makanan. Bahan berasal dari daun yang sudah dibersihkan tulang daunnya. Ukuran di sesuaikan dengan bahan makanan yang akan dibungkus. Bahan makanan yang biasa dibungkus antara lain sagu, papeda, ikan, dll. Anak daun nipah juga digunakan sebagai alat kipas-kipas api. Caranya dengan melipat anak daun nipah berbentuk segi tiga.

\section{Pucuk Daun}

Masyarakat kampung Narei menggunakan pucuk daun nipah sebagai kertas rokok (gau), perhiasan acara adat, peralatan/perlengkapan dapur dan alat gantung makanan (cili). Kertas rokok berasal dari pucuk daun nipah yang telah dilepas dari tulang daunnya kemudian dianyam berbentuk ketupat, lalu dijemur diterik matahari atau di atas para-para tungku api. Setelah kering, potong sesuai ukuran gau rokok kemudian dibelah lagi menjadi dua bagian. Bersihkan urat dalam dan siap digunakan. Selain itu masyarakat juga memanfaatkan pucuk daun tumbuhan nipah sebagai bahan pakaian adat (saat ada acara adat seperti penjemputan tamu, acara tusuk telinga, pembayaran mas kawin). Untuk membuat pakaian tersebut pucuk daun nipah dilepas dan diikat pada tali pingang. Selanjutnya pucuk daun dibelah menjadi ukuran yang lebih kecil (halus). Masyarakat juga memanfaatkan pucuk daun tumbuhan nipah sebagai alat peralatan/perlengkapan dapur. Perlengkapan wadah makanan dibuat dari anyaman pucuk daun tumbuhan nipah yang telah dilepas lidinya. Selain itu juga mereka memanfaatkan pucuk daun tumbuhan nipah sebagai alat gantung peralatan makan. Pucuk daun nipah yang telah dibersihkan lidinya lalu dianyam bentuk keranjang atau gantungan bunga.

\section{Manfaat Sosial, Budaya dan Ekonomi}

\section{Sistem Pengetahuan Tradisional}

Tentang aturan khusus atau tata cara pengambilan bagian tumbuhan nipah terdapat $96,02 \%$ masyarakat menyatakan bahwa tidak ada aturan khusus mengenai tata cara pengambilan bagian-bagian tumbuhan nipah untuk dimanfaatkan. Sedangkan untuk waktu pengambilannya (khusus bobo) sebanyak 88,24\% masyarakat menjawab bahwa ada waktu khusus yang harus diikuti/ditaati dalam mengambil tumbuhan nipah. Waktu pengambilan/penyadapan dari tumbuhan nipah atau minuman bobo yang tepat atau baik adalah pada pagi hari. Hal ini dikarenakan apabila kualitas air sadapan banyak keluar, maka bisa diambil lagi pada sore hari. Selain itu cuaca pagi lebih mendung untuk transportasi lewat laut (biasanya belum ada angin/gelombang) walaupun demikian sebanyak 54,90\% memilih sore hari. Hal ini karena alasan adanya waktu yang lebih longgar karena telah menyelesaikan pekerjaan rutin lainnya. Dalam proses pengambilan dan pemanfaatan nipah, masyarakat mengatakan tidak ada lokasi yang dilarang (sakral/pamali) untuk melakukan kegiatan tersebut.

\section{Manfaat Ekonomi}

Manfaat ekonomi dari nipah bagi masyarakat kampung Narei sulit di perhitungkan karena sebagian besar produk-produk dari nipah hanya dimanfaatkan untuk memenuhi kebutuhan sendiri (subsisten) dalam kebudayaan sosial masyarakat kampung Narei. Masyarakat hanya menjual atap dan 
minuman bobo/nira. Untuk penjualan atap, masyarakat tidak memperjual, belikan di pasar, mereka hanya menunggu ketika ada tetangga atau masyarakat lain yang memesan mereka buat. Harga yang ditentukan dalam penjualan sangat kecil, sehingga pendapatan dari hasil penjualan hanya untuk memenuhi kebutuhan keluarga, begitu juga dengan minuman bobo/nira lebih banyak untuk komsumsi sendiri. Selain itu manfaat ekonomi yang dirasakan oleh masyarakat kampung Narei tidak dapat diukur dengan satuan uang tunai yang digunakan. Hal ini karena harga jual yang ditawarkan atau kompensasi untuk bahan atap/dinding atau minuman tersebut tidak memperhitungkan biaya yang dikeluarkan oleh masyarakat untuk mendapatkan bahan baku dan biaya untuk mengerjakan produk yang dipesan. Transaksi ekonomi lebih banyak bergantung kepada situasi dan kebiasaan sosial budaya di kampung Narei (saling tolong menolong), sehingga tidak ada satuan yang jelas dalam proses jual beli didalam masyarakat kampung Narei. Lebih sering masyarakat menghargai suatu barang dengan memberikan kompensasi penukar berupa barang/jasa dan bukan dalam bentuk uang. Misalnya dengan membantu dalam penyediaan barang yang sama pada saat lain ketika penyedia barang.

\section{Pola Transfer Pengetahuan}

Seluruh masyarakat menjawab bahwa pola transfer pengetahuan tentang pemanfaatan nipah dilakukan secara nonformal (tidak melalui bangku sekolah). Di mana metode yang dipakai, hanya dengan cara bertutur/bercerita, cara diperlihatkan ataupun dengan cara dipraktekan tentang bagaimana proses pemanfaatanNipah. Sasaran dalam transfer pengetahuan umumnya/sebagian besar kepada anak/keturunan dan kerabat sedangkan transfer pengetahuan kepada orang asing/luar sangatlah kecil.

Dalam hubungannya dengan pola konservasi terlihat bahwa sejauh ini pemahaman tentang tindakan konservasi tumbuhan nipah oleh masyarakat kampung Narei masih sangat rendah. Masyarakat dengan dengan leluasa dan tidak dibatasi dalam melakukan pemanfaatan nipah baik dari intensitas pemanfaatan maupun jumlah individunya. Masyarakat kampung Narei belum melakukan kegiatan konservasi baik dalam usaha penanaman kembali, pemeliharaan, perlindungan maupun pemberian sanksi.

\section{DAFTAR PUSTAKA}

Asmuruf SS. 2006. Teknik memproduksi nira nipah (Nipah fruticans Wurmb.) secara tradisional oleh suku Maibrat di Kampung Gaya Baru, Bintuni. Fakultas Kehutanan Universitas Papua Manokwari. (tidak diterbitkan). Badan Pusat Statistik Kabupaten Yapen 2017. Kabupaten Kepulauan Yapen Dalam Angka. Badan Pusat Statistik Kepulauan Yapen.

Bandini Y. 1996. Nipah pemanis almi, PT Penebar Swadaya. Jakarta.

Febriadi I dan Saeni F. 2018. Inventarisasi dan pemanfaatan nipah (Nypa fruticans (Thunb.) Wurmb.) oleh masyarakat pada hutan mangrove Kampung Mariat Pantai Distrik Aimas Kabupaten Sorong. Median, Vol 10 (3): 23-30.

Inwasef Y. 2011. Pemanfaatan tumbuhan nipah (Nypah fruticans, Wurmb.) oleh masyarakat Kampung Mariarotu Distrik Kosiwo Kabupaten Kepulauan Yapen. Fakultas Kehutanan 
Universitas Papua Manokwari. (tidak diterbitkan).

Muthmainnah dan Sribianti I. 2016. Nilai manfaat ekonomi tanaman nipah (Nypa fruticans) Desa Lakkang Kecamatan Tallo Kota Makassar. Jurnal Hutan Tropis, 4 (2): 140-144.
Subiandono E, Heriyanto NM dan Karlina E. 2011. Potensi nipah (Nypa fruticans (Thunb.) Wurmb.) sebagai sumber pangan dari hutan mangrove. Buletin Plasma Nuftah, 17 (1): 54-60. 